\title{
Struggle for Rights to Health Equity and Social Justice: Remembering Professor David Sanders
}

Madhusudan Subedi

\begin{abstract}
Professor David Sanders, a well-renowned academic, consummate activist and commentator, and a great public intellectual, passed away on $30^{\text {th }}$ August 2019 at the age of 74 . He was a champion of economic and social justice, being one of the pioneers who argued for the importance of primary health care. He emphasized the importance of involving communities, particularly that health workers should be accountable to communities and play a crucial role in promoting health and preventing disease. This paper highlights David Sanders' contribution in public health teaching, research, and advocacy for almost five decades.
\end{abstract}

Keywords: public intellectual, people's health movement, struggle for health, David Sanders

\section{Introduction}

Professor David Sanders, a beloved colleague, friend, mentor, and activist passed away on $30^{\text {th }}$ August 2019 whilst on holiday in Wales, UK. He had a heart attack after a fishing trip, one of his favorite and relaxing hobbies. David was a fierce critic of the impact of neo-liberalism on people's health. He was an internationally acclaimed researcher, academic and mentor, and also a leader of social movements, including the People's Health Movements. He advocated human and health rights, and was a voice for the voiceless. He was always concerned about the influx of processed foods from the west which have negative effects not only on the economy of developing countries, but also on the health of poor people.

In this tribute to David, it is impossible for me to fully capture who David actually was. I present a short biography of David, his involvement in People's Health Movement (PHM), our professional relationship, his commitment to fight against health inequality, his emphasis on primary health care, and the special attention to be given to public health research. The information presented below is taken from published documents, web pages, and from an interaction with him during his visit at Patan Academy of Health Sciences (PAHS), Nepal. I have freely borrowed words from tributes to Professor Sanders made by various intellectuals.

\section{A Short Biography}

David was born in South Africa in 1945. He grew up in Zimbabwe where he qualified as a medical doctor. During the 1970s, he lived in the UK, where he specialized in pediatrics and public health. During his time in the UK, David was actively involved in the liberation movements. He returned to newly independent Zimbabwe in 1980, and worked at the University of Zimbabwe's Medical School. There he established the first rural placement for medical students. He also helped the government to initiate a rural health program with a focus on household-level health promotion and prevention by community health workers. In the early 1990s, David returned to South Africa to work at the University of KwaZulu-Natal. From there, he moved Cape Town to establish the Public Health Program at the University of Western Cape in 1993, and became its founding director. He led the school until 2009. During his years there he developed a world-renowned distance learning Masters in Public Health that graduated students from all over Africa.

David had over 40 years of experience in health policy and program development in Zimbabwe and South Africa, and worked extensively with governments, World Health Organization (WHO), United Nations International Children's Emergency Fund (UNICEF), and other agencies in child health, nutrition, and health human resources. David had extensive experience within primary health care, child health and nutrition, and human resources for

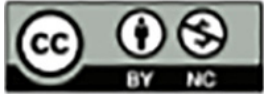

This work is licensed under the Creative Commons $\mathbb{C}$ Madhusudan Subedi

Madhusudan Subedi: Patan Academy of Health Sciences

Email: madhusudansubedi@gmail.com/https://orcid.org/0000-0001-6495-0601 
health as part of health systems development. He was active in various civil society organizations that promoted social justice and Health for All.

David was Heath Clark Visiting Lecturer at the London School of Hygiene and Tropical Medicine in 2005, and an Honorary Professor at that institution from 2005 to 2007. He was a Visiting Professor at Charité Universitätsmedizin in Berlin as well as at the Centre for International Health, University of Bergen, Norway, with which he continued to collaborate. He was appointed as Honorary Professor in the Department of Paediatrics and Child Health, Faculty of Health Sciences, University of Cape Town (UCT) South Africa from July 2013, and as Professor in the School of Medicine, Faculty of Health Sciences, Flinders University of South Australia from August 2013.

In 2012, David was awarded an Honorary Doctorate by UCT in recognition of his contribution to developing policies and programs in primary health care nationally and internationally. In 2013, he received the International Academic Partnership Merit Award from the Faculty of Medicine, University Eduardo Mondlane, Mozambique, and, in 2014, he received the Public Health Innovation and Lifetime Achievement (PHILA) Award from the Public Health Association of South Africa (PHASA).

He was on the Steering Committee of the United Nations Standing Committee on Nutrition from 2002 to 2006, and a member of the Knowledge Network of the WHO Commission on Social Determinants of Health. He was a founding member of the UK Politics of Health Group, of the International People's Health Council, and of PHM. He was a managing editor of Global Health Watch2.

David was key in shaping the WHO Commission on Social Determinants of Health, and had strongly advocated in making civil society engagement meaningful, authentic and impactful. He had emphasized that the public health revolution should move from charity model to one that recognizes rights of citizenship and to a focus on the political determinants of health. David was a founding member of People's Health Movement (PHM) in 2000 in Savar, Bangladesh, and, until his death, the Co-chair of PHM.

David was involved extensively in the political economy of health, including on structural adjustment and development aid. He had co-authored three books: The Struggle for Health: Medicine and the Politics of Underdevelopment (1985), Questioning the Solution: the Politics of Primary Health Care and Child Survival (1997) and Fatal Indifference: the G8, Africa and Global Health (2004), as well as many chapters and journal articles. He had a long involvement in capacity development of health personnel, having previously worked in the Medical Schools of the Universities of Zimbabwe and Natal. David was always optimistic and had envisioned 'global non-violent revolution' to unify disempowered people in demanding accountability of governments, the United Nation's agencies and international financial institutions.

In the UK, as a political emigré from Rhodesia, he trained in paediatrics and became a founding member of the Medical Association against Private Practice. At St Thomas's hospital in London he learned much "about the British Class system".
At the London School of Hygiene and Tropical Medicine he became an advocate for the 1978 Alma Ata Declaration on primary health care, and was influenced by the writings of the Marxist doctor Vicente Navarro. David was always passionate about participatory socialist democracy as a way to improve health and reduce inequality.

\section{Commitment to People's Health Movement}

The PHM is a global network bring together grassroots health activists, civil society organizations and academic institutions particularly from lower and middle income countries guided by people's charter for health and is committed to comprehensive primary health care and addressing the social, environmental and economic determinants of health (for more information, please visit: phmovement.org). Sustainable development and peace are at the heart of PHM mission. The PHM promotes health for all through an equitable, participatory and intersectoral movement; advocates for government and other health agencies to ensure universal access to quality health care, education, and social services according to people's need; promote the participation of people and people's organization in the formulation, implementation and evaluation of all health, social policies and programs; and encourage people to develop their own solutions to local health problems.

People's health assembly (PHA) is a unique space for sharing experiences, mutual learning, and joint strategies for future direction of PHM. The first PHA was held in Savar, Bangladesh in December 2000 and was attended by more than 1453 people from 75 countries (https:// phmovement.org/about/).

In 2000, David played a leading role in establishing the PHM, especially among the younger generation that should learn more about the history of health activism. In the PHM, he was a leading critic of structural adjustment, neoliberal economics, and how social and economic inequalities lead to poor health. His research and books have highlighted the links between social and political injustice as the root cause of maternal and child ill-health. His leadership and engagement with the PHM created a favorable environment for more voices to feed into the global health policy discourse.

During a week residential PHM workshop for South Asia (22-29 November, 2016) in Kathmandu, he highlighted that in South Africa, large commercial entities that dominated the agricultural, food and beverage environment, was getting more widespread, and that this implicated unhealthy eating. A few huge industries dominate the production and sale of food and drink to consumers. These 'big food' companies have developed strategies to increase the availability, affordability and acceptability of their food items in South Africa. He suggested that the African and Asian governments should act urgently to mitigate the adverse health effects through education about the health risks of unhealthy diets, of the need to regulate 'big food', and to support healthy food. David highlighted that the big companies want to separate 
what people eat from the food's origin, and most important thing to these companies is profit. He also emphasized on the empowerment of the local trade which can improve the socio-economic status of the family and community.

I enjoyed his wisdom, humor, and friendliness during a week residential program of PHM South Asia in Kathmandu. We shared a common commitment to the 1978 Alma Ata Declaration, to the concept of comprehensive primary health care, and to the training of community based health workers. Our goal was for Health for All.

\section{Professional Relationship with Patan Academy of Health Sciences (PAHS)}

I was deeply saddened to hear the passing of this renowned public health scholar, a great friend, and a big supporter of PAHS School of Public Health Program. His insightful book, The Struggle for Health: Medicine and the Politics of Underdevelopment, co-authored with Richard Carver in 1985, opened my eyes for inequalities in health, present and past. He demonstrated that the reduction of illness and premature mortality in the UK was the result of improved living standards and hygiene, and only to a very limited extent from specific preventive measures and curative services (Sanders \& Carver, 1985). He highlighted that transplantation into low and middle income countries of the western health system was part of the broader process of expanding the capitalist system, adding that western health systems are more concerned with the medical profession and the commercial interests rather than people's wellbeing. He appealed to expatriate health workers to make available to their home country what they had learned in order to make primary health care the basis of its health care system, and facilitate democracy and transparency in health management. The book was very important for making me, and many others, aware of the need of effective primary health care in developing countries like Nepal. I have read him so many times that I feel like he was my personal friend.

I met David for the first time 2011 at Patan Academy of Health Sciences. His amazing insight and critical appraisal of determinants of people's health were fueled by his genuine concern and his ability to learn from those at the grassroots.

He used tell many stories with political jokes related to the power dynamics and how capitalism had created inequalities in human society. With the jokes he used to justify the importance of looking for the causes of poor health. Every time he spoke, I observed people identifying with his messages about the contesting power structures, the medical hegemony, the importance of defending the PHC principles of the Alma Ata Declaration, and the arguments for building a movement from the bottom up.

David was a special friend of PAHS. Dr Arjun Karki, the Founding Vice Chancellor of PAHS invited him during the curriculum development workshop. His shared the experiences of UCT and highlighted theoretical and methodological opportunities and challenges for innovative curriculum. We developed and, are implementing competency driven module-based course. It is delivered through project-cycle approach enabling integrated delivery of contents from major areas of public health disciplines. As a Coordinator of the School of Public Health Program, I realize that David was not just our special friend, but also a mentor for the preparation of the Master of Public Health curriculum. During a grand round at PAHS in 2012 he focused on various issues: that national life expectancy was increasing while regional differences remained; the growing inequalities between Sub-Saharan Africa and higher income countries; nutrition as a key determinant of health; food insecurity; and that poverty was a fundamental determinant of health conditions.

\section{Fighting Health Inequality}

David was clear in his views and perspectives. His commitment to social justice and support for the voices of the marginalized to feed into health policy and planning, inspired hundreds of health workers globally. His vision of Health for All was very clear. David imbued global health politics with a clear vision that social justice could be brought about within, and by the workers, in the health sector.

David was not impressed by political privilege or power; he shared his visions, promoted and encouraged young health professionals to choose the option of health for all and, at the same time, was a consummate public health professional with equal respect for science, research and social activism.

He used to tell that all people should be valued equally. Every person should be able to achieve his or her health status without regard to characteristics that historically have been linked to marginalization and/or discrimination. Every person should be able to enjoy international standards of human rights commit governments to promote and respect the right to the best possible health condition. As suboptimal health can be an obstacle to overcoming social disadvantages, health differences among socially deprived groups are exceptionally objectionable, therefore, resources crucial for good health should be allocated fairly.

David has in his writings and public speaking that it is impossible to describe health care equity and health care disparity without considering the notion of 'social disadvantage'. Social disadvantage refers to those conditions some people systematically endure based on their relative status within a social hierarchy. This could be based on lack of political representation, low income, occupational rank, literacy level, or education. Health disparities or inequities impact disadvantaged groups by actually putting them in situations where overcoming the social disadvantage can be more difficult.

Social justice and ethical principles were other important issues of David Sanders. Within the health care system, justice implies that persons with the same medical conditions should have access to the same treatment options. This goal puts focus on persons and groups that control the distribution of services or merchandise.

Social justice serves as a catalyst for all health care providers to promote social change. Clearly many health care providers face barriers. Nurses and physicians 
may feel that legislative policies and politics impose insurmountable obstacles for social change, giving them a sense of disempowerment, disillusionment, and futility. However, nurses and doctors are socially better positioned to apply ethical human rights principles to improve the health conditions of the disadvantaged patients and groups they serve.

Tackling health equity in a meaningful way means confronting the social determinants at the root of poor health and engaging the officials and community stakeholders who are well positioned to drive change. David offered analysis of the root causes of inequality and poor health, and guidance to young social and health activists about how to tackle contemporary challenges for health, the environment, gender and inequality.

David identified the key underlying causes of global health inequalities: poverty, increasing wealth and income inequalities worsened by neoliberal globalization, selective public health care and, inappropriate health sector 'reform'. Economic and social determinants of health include employment levels and conditions, food and diets, the environment, and climate change.

Sanders and Chopra (2006) argued that despite constitutionally enshrined social and economic rights and universal pro-equity policies, deep inequalities persisted. This situation requires a different approach to resource allocation and quality of caring processes, advocacy efforts, and community member involvement to enhance their capacity to make demands for health equity. They argued that bridging the continuing gap between health policy and reality requires more explicit targeting of resources through measurement of key disparities in health needs, and to use effective technologies to address these needs. Fundamentally, this involves some sort of collaboration between local community-based structures and personnel, and state agents who have technical skills. They argued that advocacy and community mobilizations are the keys to securing the accountability and the political will that are necessary for obtaining more equitable resource allocation.

\section{From Alma Ata to Asthana}

The historic 1978 Alma Ata Conference stated that primary health care ( $\mathrm{PHC}$ ) was the best means to achieve health for all by the year 2000. The principles of PHC included universal access and equitable coverage; comprehensive care emphasizing disease prevention and health promotion; community and individual participation in health policy, planning, and provision; inter-sector action on health determinants; and appropriate technology and cost-effective use of available resources (Sanders et al., 2019). These principles should form the basis for health care throughout the health system focusing primarily on maternal and child health, communicable diseases, and local social and environmental issues. PHC emphasized community participation through a network of workers who would be trained both socially and technically.

David had a clear vision regarding primary health care. He shared his view with Nepali public health colleagues that public health professionals should have a clear idea regarding 'primary health care' and 'primary care'. Primary care is largely clinical, having to do with behavior of health service professionals and their interaction with people, and, increasingly, with particular groups they provide services for.

Sanders et al. (2019, p. 619) argued: UHC is concerned with improved access to quality health services and protection from financial risks associated with health care. However, UHC, unlike PHC, is silent on social determinants of health and community participation. With the global mobilization behind UHC, the health sector will probably limit its role to Sustainable Development Goal (SDG) 3.8 to achieve UHC. This shift in policy emphasis for the health sector threatens to minimize its role in promoting other healthrelated SDGs such as food and nutrition (SDG 2), gender equality (SDG 5), and water and sanitation (SDG 6); and, importantly, the reduction of inequality (SDG 10), promotion of environmentally responsible consumption/ production patterns (SDG 12), and mitigation of climate change (SDG 4).

Sanders et al. (2019, p. 619) wrote:

the term coverage rather than care either suggests a limited scope of care or is being used to suggest enrolment in an insurance scheme. For many lower and middle-income countries, this has meant operationalizing universal health coverage (UHC) through governmentfunded health insurance schemes. The adverse implications are seen in countries such as India, where coverage by publicly funded health insurance has neither been equitable nor led to financial protection. Involving the for-profit private sector in providing health care has allowed funding imbalances and provider capture, with more funds from these public schemes going into the private health sector, thereby reinforcing existing health inequities. Insurance-based models of UHC risk being promoted at the expense of funding PHC and other public health programs.

During the 40th anniversary celebration of Primary Health Care (PHC) in 2018 at Astana, references were repeatedly made to "quality PHC", and that primary care meant care at the first level of contact with the formal health sector. David represented PHM and presented in a session and re-affirmed commitment to PHC in pursuit of health and well-being for all, aiming to achieve equity in health outcomes.

David was highly concerned on medical care services, and the expansion of insurance coverage that had displaced public health and the social determination of health. Although the Declaration of Astana invokes PHC frequently, it gives scant attention to the drivers of ill health and inequity. The Declaration of Astana, however, avoided the challenge of what needs to happen from within the health sector to mitigate inequality: Inter-sector action at local and policy levels, and strong advocacy from the health constituency to reverse the processes leading to 
unsustainable inequalities and planetary destruction. Instead, Astana calls for "partnership" with the private sector, notwithstanding the mounting evidence of the commercial determinants of poor health such as alcohol, tobacco, ultra-processed foods, and industrial and automobile pollution. National public authorities' call for "private sector regulation" to manage conflicts of interest fails to recognize that such authorities, especially in LMICs, are often unable or unwilling to regulate the private sector. The power of transnational corporations transcends national boundaries and requires strong and decisive action both by global civil society and international institutions.

\section{Making Research Matter}

David throughout his life engaged in in-depth constructive research. His activism was research based (Watts, 2019), and he guided and inspired a number of students and public health professionals. He always challenged established notions and pushed everyone towards a critical way of thinking. In his book Struggle for Health, he wrote that the success of applying medical technology to the benefit of society critically depends on the political context in which it is applied. He aimed to minimize the barrier between academia and activism. He always advocated that research should focus on global, national and local health factors. He emphasized that the civil society organizations (CSOs) can play an important role by influencing, generating or using such research. He meant that any health research about individuals' or groups' everyday lives should provide a civil society perspective. Also, equal relationships between researchers and community members could increase the relevance of research to CSOs (Sanders et al., 2004).

David said that health research must prioritize some key issues. First, examine the cause of the increasingly unequal burden of poor health between and within countries. Second, implementation should focus on individual service provisions, community governance models, detailed case studies of comprehensive primary health care and population-based studies of factors influencing the success of interventions, and to measure their impacts. Third, identifying strategies for social change by analyzing what forms of social mobilization - local, national and global are best able to effect policy changes for improving health systems (Sanders et al., 2004).

David had given to producing evidence of the negative aspects of globalization and its effects, and of the positive health impact of equitable health policies. In this way, David used to argue, we can contribute to the achievement of the laudable but receding goal of responsible and responsive local and global governance and thereby address the determinants of health (Sander, 2006). David was worried about the lack of equity in funding research into these issues.

\section{Conclusion}

David inspired the world in significant global health issues. David brought an important and consistent voice to the global discourse on equity and social justice. The way he combined his academic work with being a public intellectual, a commentator on health issues, and an activist, was an impressive achievement. The untimely demise of David is an irreparable loss to all of us and for the broader health movement globally. PHM-Global and PHM-South Africa will continue to carry forward David's vision of strengthening the people's health movement.

Our most significant gift to David would be to carry on the fight for the right to health for all. To continually share stories when health is denied to populations and to continue to fight for the implementation of the Alma Ata principles through increasing equity and voice through an inter-sector approach. David passionately wanted health for all, but also a new world order, based not on capital accumulation but rather on compassion, equality, mutual aid, and social justice. Gratitude to David flows partly from that legacy. One of the most beautiful tributes to David would be to read and re-read his academic contributions, understand and adopt his approaches in public health reform in Nepal and around the world. Long live David Sanders! Your role in advancing social justice in health globally is unforgettable. Your works and life is a message to so many people.

\section{Acknowledgements:}

A part of this writing was presented on 26 November 2019 in Martin Chautari, Kathmandu. The title of the presentation was 'Revisiting David Sanders' Work and Life: An Obituary to the Pioneer of People's Health Movement'. I would like to thank Professor Marit Bakke for her helpful comments and suggestions. I thank the anonymous reviewers for their careful reading of manuscript and their insightful comments and suggestions.

\section{Funding:}

Not funded

\section{Ethical approval for the research:}

Not Applicable

\section{Conflict of Interest:}

Researcher does not have any conflict of interest.

\section{Ethical Conduct of Research:}

I declare that this review has been conducted ethically

\section{References}

Labonte, R., Shrecker,T., Sanders, D., and Meeus, W. (2004). Fatal difference: the g8, africa and global health. University of Cape Town Press.

Sanders, D. (2006). A Global perspective on health promotion and the social determinants of health. Health Promotion Journal of Australia, 17(3),1657.

Sanders, D.(1990). Equity in health: Zimbabwe nine years on. Journal of Social Development in Africa, 5(1), 5-22.

Sanders, D., Nandi, S., Labonté, R., Vance, C., \& Van Damme, W. (2019). From primary health care to 
Sanders, D., with Carver, R. (1985). The struggle for health: medicine and the politics of underdevelopment. Macmillan Education.

Watts, G. (2019). Obituary. The Lancet, 394, 1238.

Werner, D., and Sanders, D. (1997). Questioning the solution. The Politics of Primary Health Care and Child Survival. Health Wrights.

Madhusudan Subedi is Professor and Chairperson of the Department of Community Health Sciences and Coordinator of the School of Public Health, Patan Academy of Health Sciences. He is also associated with the Central Department of Sociology, Tribhuvan University, Nepal.

Email: madhusudansubedi@gmail.com 